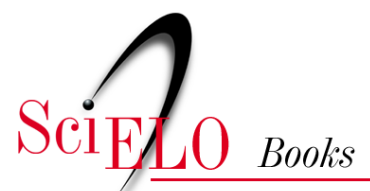

\title{
$\underline{\text { 3. O feito por fazer }}$
}

\author{
Moisés Goldbaum
}

Rita Barradas Barata

\section{SciELO Books / SciELO Livros / SciELO Libros}

GOLDBAUM, M., and BARATA, R. B. O feito por fazer. In: LIMA, N. T., and SANTANA, J. P., eds. Saúde coletiva como compromisso: a trajetória da Abrasco [online]. Rio de Janeiro: Editora FIOCRUZ; Abrasco, 2006, pp. 79-115. ISBN: 978-65-5708-156-3. https://doi.org/10.7476/9786557081563.0004.

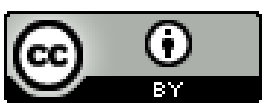

All the contents of this work, except where otherwise noted, is licensed under a Creative Commons Attribution 4.0 International license.

Todo o conteúdo deste trabalho, exceto quando houver ressalva, é publicado sob a licença Creative Commons Atribição 4.0.

Todo el contenido de esta obra, excepto donde se indique lo contrario, está bajo licencia de la licencia $\underline{\text { Creative }}$ Commons Reconocimento 4.0. 


\section{O Feito Por Fazer}

\section{O FEITO}

$A$ forte tradição presidencialista da política brasileira repercute na maioria das nossas instituições, e as sociedades científicas dificilmente conseguiriam fugir a essa regra. A Associação Brasileira de Pós-Graduação em Saúde Coletiva (Abrasco) também teve em seus presidentes figuras emblemáticas que, juntamente com os demais membros de suas respectivas diretorias, desempenharam papéis de formulação, articulação e condução do movimento em seus três eixos principais: formação de recursos humanos em Saúde Coletiva, produção de conhecimentos técnico-científicos e Política Nacional de Saúde. Neste capítulo, procuraremos articular as características de cada diretoria, representadas na figura do presidente, com a problemática específica de cada período e os desafios enfrentados, destacando suas realizações no âmbito daqueles três eixos.

A primeira diretoria encarregada de organizar os estatutos da associação, bem como obter seu registro, foi composta pelos professores Ernani Braga, Guilherme Rodrigues da Silva, José da Silva Guedes e Frederico Simões Barbosa, ficando este último com a presidência. Essa etapa de criação da Abrasco, de 1979 a 1981, foi dedicada praticamente à resolução dos problemas operacionais da nova entidade: local de instalação de uma secretaria geral, obtenção de fundos para iniciar os trabalhos e preparação da primeira eleição, uma vez que os membros dessa primeira diretoria haviam sido eleitos por aclamação entre os '19 fundadores', segundo Benedictus Philadelpho. 
Embora o tripé pesquisa, ensino e serviços de saúde já estivesse presente no ideário da associação, os objetivos apresentados em seu documento preliminar dão ênfase principalmente às atividades de ensino e pesquisa. Não poderia ser diferente, pois o grupo fundador era composto por docentes dos departamentos de medicina preventiva e/ou social das escolas médicas brasileiras, além de docentes da Escola Nacional de Saúde Pública, da Faculdade de Saúde Pública da Universidade de São Paulo (USP) e do Instituto de Medicina Social da Universidade do Estado do Rio de Janeiro (IMS/Uerj).

Frederico Simões Barbosa foi um conceituado e respeitado parasitologista com experiência em estudos populacionais de campo, representante de toda uma tradição da parasitologia brasileira de trabalhos em Saúde Pública. Associava a militância política pela saúde da população e pela renovação do ensino médico no país a uma atuação sólida e marcante como docente e pesquisador. Ninguém melhor para representar os anseios da nova associação. Após estágio de especialização, realizado no grupo de Samuel Pessoa, com uma bolsa concedida por Assis Chateaubriand, dos Diários Associados, fez mestrado em Saúde Pública na Universidade Johns Hopkins, estabelecendo vínculos de pesquisa com os National Institutes of Health que lhe valeram diversos financiamentos para seus trabalhos de campo, principalmente no tema da esquistossomose. Dirigiu o programa de esquistossomose da Organização Mundial da Saúde (OMS) e ocupou diversos cargos docentes na Universidade de Brasília (UnB) e na Universidade Federal de Pernambuco (UFPE). Após exercer a presidência da Abrasco, assumiu a direção da Escola Nacional de Saúde Pública (19831985) e seguiu trabalhando como pesquisador do Centro de Pesquisas Aggeu Magalhães, da Fundação Oswaldo Cruz (Fiocruz), até a sua morte.

No momento de criação da Abrasco, o desenvolvimento da pósgraduação no país ainda era relativamente incipiente. Os cursos de mestrado e doutorado estavam concentrados em apenas três estados e quatro instituições: São Paulo (USP, campi de São Paulo e de Ribeirão Preto), Rio de Janeiro (Uerj e Escola Nacional de Saúde Pública - ENSP) e Bahia (Universidade Federal da Bahia - UFBA). A pesquisa científica no campo também era incipiente e subfinanciada.

No âmbito da formação profissional, destacavam-se os cursos de especialização em Saúde Pública oferecidos pela Faculdade de Saúde Pública da USP e pela Escola Nacional de Saúde Pública e as residências médicas em medicina preventiva e medicina social, oferecidas por alguns departamentos de escolas médicas (13 programas no final da década de 70) também geograficamente concentrados na Região Sudeste. 
Durante toda a década de 70, foram gestados, nesses espaços acadêmicos, tanto o desenvolvimento teórico e conceitual que permitiu a construção do campo da Saúde Coletiva quanto as propostas de organização do Sistema Nacional de Saúde que dariam conteúdo ao movimento da Reforma Sanitária brasileira. As idéias de integração das ações de Saúde Pública com as ações assistenciais em um único sistema, sob o comando do Ministério da Saúde, de regionalização e de hierarquização das redes de serviço e de universalização do acesso, entre outras, são produzidas, debatidas e divulgadas nos encontros de docentes de medicina preventiva e social e em seminários e reuniões dos programas de residência médica.

Assim, a Abrasco surge como associação principalmente de docentes dos departamentos de medicina preventiva, medicina social e escolas de Saúde Pública, com predomínio inicial do componente médico sanitário. Os problemas que mobilizam esses atores são o ensino e a formação de profissionais e pesquisadores em Saúde Coletiva, além das questões relativas à organização do Sistema Nacional de Saúde.

Seu primeiro presidente e os demais membros dessa diretoria representam, por suas trajetórias profissionais, exatamente essas três dimensões: a docência, a pesquisa e a prática em Saúde Pública. Findo o primeiro triênio da história da Abrasco, ela contava com uma sede na Escola Nacional de Saúde Pública, com recursos financeiros da Fundação Kellog para apoiar as atividades nos primeiros três anos, um secretário executivo dinâmico e dedicado, Paulo Buss, e um conjunto inicial de sócios institucionais e individuais que compartilhavam das preocupações acerca das prioridades para o ensino, a pesquisa e a política de saúde, vendo no movimento associativo uma saída para buscar conjuntamente a superação de vários problemas.

A segunda diretoria, eleita para o triênio 1981-1983, foi composta por Benedictus Philadelpho de Siqueira, na presidência, José da Silva Guedes, Jairnilson Paim e Ernani Braga nos demais cargos. A secretaria executiva continuava a cargo de Paulo Buss.

Benedictus Philadelpho, o Phila, era professor do Departamento de Medicina Preventiva da Universidade Federal de Minas Gerais (UFMG) e militante da Associação Brasileira de Ensino Médico (Abem), buscando sempre o aprimoramento da formação profissional e a modernização do ensino. Em sua gestão, a formação de recursos humanos e o mercado de trabalho para os profissionais da Saúde Coletiva ocuparam lugar central.

O maior desafio da gestão foi manter as residências de medicina preventiva e social com suas características de formação de sanitaristas. A partir de 1979, com a entrada do Ministério da Previdência Social no 
financiamento das bolsas de residência médica nessa área, houve considerável expansão dos programas e vários deles foram constituídos em moldes multiprofissionais, mais adequados às características e exigências do campo da Saúde Coletiva. Em 1981, com a regulamentação da residência médica e a constituição da Comissão Nacional de Residência Médica, houve a tentativa de extinção dos programas de medicina preventiva e social e a substituição por programas de medicina geral e comunitária, com nítido esvaziamento do componente de Saúde Coletiva e a concentração de atividades de atenção primária. A manobra visava, principalmente, impedir a politização da questão da saúde, presente na formação dos profissionais sanitaristas.

O crescimento dos programas de residência foi acompanhado também pelo crescimento da oferta de cursos regionalizados de especialização em Saúde Pública coordenados pela ENSP em colaboração com escolas de Saúde Pública ligadas às secretarias de Saúde dos estados. Os programas de pós-graduação estrito senso permaneceram ainda restritos nesse período, assim como a produção científica da área. Por outro lado, a constituição efetiva da associação demandava da diretoria iniciativas de articulação dos docentes e a elaboração de um ideário compartilhado relativo ao campo em si e à Política Nacional de Saúde.

O primeiro desafio foi vencido com a articulação dos coordenadores dos programas de residência e a elaboração e aprovação da Resolução 16/1981, que mantinha as características de formação em Saúde Coletiva para os residentes de medicina preventiva e social e a diferenciava claramente da formação em medicina geral comunitária, regida por outra resolução.

O segundo desafio foi enfrentado por meio de duas iniciativas: a realização de reuniões nacionais de ensino e pesquisa em epidemiologia, ciências sociais em saúde e planejamento e administração em saúde congregando os docentes por vertentes disciplinares constitutivas do campo da Saúde Coletiva; e a realização de seminários nacionais por modalidades de ensino, ou seja, residência médica, cursos regionalizados de Saúde Pública e programas de mestrado e doutorado, cobrindo assim toda a gama de oferta de formação acadêmica e profissional no campo.

Para fortalecer essas iniciativas de articulação docente, a Abrasco começou a concretizar seu projeto editorial, editando o boletim que permanece ativo em meio eletrônico e na forma impressa e a série Estudos de Saúde Coletiva, publicação na qual são divulgados os documentos preliminares, bem como os relatórios de reuniões e seminários nacionais, fornecendo assim um instrumento muito útil para o compartilhamento de 
idéias no interior do campo, para além dos momentos de reunião dos seus docentes.

Mais uma vez, o perfil profissional do presidente se mostrava o mais adequado para o enfrentamento dos problemas dessa conjuntura, na qual as questões de ensino e formação profissional ocupavam o centro das preocupações. Evidência desse acerto são as realizações do período, mas também as funções de direção exercidas por Philadelpho na Abem e na própria UFMG, após deixar a presidência da Abrasco. Evidentemente, essa formação não poderia se dar no vazio, sendo imprescindível o diálogo permanente com a esfera da política de saúde e as propostas de reforma do setor que começaram a ganhar fôlego, na esteira dos movimentos políticos e sociais que marcaram esse período de transição entre a ditadura e a redemocratização do país.

Em 1983, realizou-se o primeiro congresso nacional da Abrasco em conjunto com a Associação Paulista de Saúde Pública (APSP). Neste evento, a participação da associação foi pontual. O tema central era a Política Nacional de Saúde desdobrado em Política de Assistência Médica, Política de Saneamento, Política de Recursos Humanos e Participação Popular em Saúde. A Abrasco se encarregou de organizar a mesa-redonda sobre a Política de Recursos Humanos e dois painéis sobre ensino de Saúde Coletiva.

No congresso foi eleita a nova diretoria, encarregada de conduzir a associação durante o triênio 1983-1985, composta por Hésio Albuquerque Cordeiro, José da Rocha Carvalheiro, Francisco Eduardo Campos, Tânia Celeste Matos Nunes e Paulo Buss. Hésio Cordeiro era, nessa época, professor adjunto do Instituto de Medicina Social da Uerj, onde desenvolvia atividades de ensino de graduação e pós-graduação e investigações científicas no campo da Saúde Pública, privilegiando, em sua produção intelectual, as questões referentes à organização dos serviços de saúde e as questões de ensino. Após o final do mandato na presidência da Abrasco, assumiu a presidência do Instituto Nacional de Assistência Médica da Previdência Social durante a 'Nova República', implementando a estratégia do Sistema Unificado e Descentralizado de Saúde (Suds), preparando assim as condições para a fusão entre Ministério da Saúde e Instituto Nacional de Assistência Médica da Previdência Social (Inamps) que ocorreu com a criação do Sistema Único de Saúde (SUS). Na década de 90, desempenhou papel destacado no Conselho Nacional de Educação.

A trajetória do presidente Hésio Cordeiro mais uma vez corporifica as linhas de atuação da associação, apresentando desdobramentos nos três eixos de atuação: ensino, pesquisa e política de saúde. Sua participação como presidente do Inamps permitiu a concretização de muitas das 
aspirações do movimento sanitário brasileiro, possibilitando a passagem da 'teoria' para a 'prática', fundamental para o fortalecimento político do movimento organizado em torno da Abrasco e de entidades congêneres ou próximas como o Centro Brasileiro de Estudos de Saúde (Cebes), ainda que nem sempre houvesse coincidência de propósitos ou estratégias de ação.

Essa diretoria continuou o trabalho de organização desenvolvido pelo grupo que a precedeu, dando prosseguimento à realização de seminários e reuniões nacionais e criando as comissões encarregadas especificamente do fortalecimento da epidemiologia, das ciências sociais em saúde e do planejamento e administração em saúde.

Continuando seu trabalho de melhoria dos padrões de ensino e formação profissional, a Abrasco dedicou maior atenção à preparação de docentes e introduziu em sua agenda a questão do ensino da Saúde Coletiva nos cursos de graduação. No âmbito da residência médica, a questão candente passou a ser a regulamentação da residência multiprofissional, o que, a despeito dos esforços dessa época, só ocorreria em 2005.

Ao lado das atividades voltadas preferencialmente para o ensino e a formação de recursos humanos que até então haviam estado no centro da atuação da Abrasco, a terceira diretoria desenvolveu uma série de articulações com as agências de fomento visando incluir a Saúde Coletiva entre as áreas de desenvolvimento científico e tecnológico no país. Esse esforço estava associado ao estímulo à introdução de novos conteúdos e metodologias na pesquisa objetivando a construção de um campo efetivamente interdisciplinar.

O país estava vivendo seu processo de redemocratização política mostrando ao movimento sanitário a necessidade de engajamento nas reivindicações pela 'Anistia ampla, geral e irrestrita' e pelas eleições diretas para os cargos executivos de prefeitos, governadores e presidente, aspiração do movimento pelas 'Diretas Já'. Assim, a Abrasco apresentase na arena política ao lado de outros movimentos sociais civis organizados. Apesar da pouca idade, a associação encerra aqui sua fase de constituição fortemente marcada pelo interesse na formação de profissionais de saúde e inicia uma etapa de grande participação nas definições dos rumos da política de saúde.

A quarta diretoria, gestão 1985-1987, foi presidida por Sebastião Antônio Loureiro de Souza e Silva e composta por Sônia Fleury Teixeira, Moisés Goldbaum, Eduardo Freese de Carvalho e Paulo Buss. Sebastião Loureiro, professor adjunto do Departamento de Medicina Preventiva da Universidade Federal da Bahia, exercia atividades docentes na graduação e na pós-graduação e realizava pesquisas no campo da Saúde Coletiva 
com ênfase no estudo da epidemiologia de doenças transmissíveis e de suas relações com as condições de vida da população.

$\mathrm{O}$ que caracterizou essa gestão foi a definição da Abrasco como um dos atores políticos relevantes na formulação e implementação da política de saúde no contexto político de redemocratização do país. A criação da Comissão de Política de Saúde, encarregada de elaborar o documento básico que orientaria a atuação da Abrasco nas etapas preparatórias e durante a VIII Conferência Nacional de Saúde, "permitiu a ampliação da participação de outros companheiros na luta pelo direito à saúde", segundo Sebastião Loureiro.

O documento "Pelo Direito Universal à Saúde", elaborado pela Comissão de Política de Saúde e aprovado pelos membros de todas as comissões e pela diretoria, com tiragem de cerca de 17 mil exemplares, transformou-se, praticamente, no documento básico debatido em toda a fase preparatória e também durante a conferência nacional. Em linhas gerais, o documento apresentava quatro aspectos que acabaram por balizar as discussões: o direito à saúde como direito universal e inalienável de todos os homens; o dever do Estado de prover as condições para efetivação desse direito; o conceito ampliado de saúde explicitando o caráter necessariamente intersetorial que as ações de promoção, proteção e recuperação da saúde devem ter; e a importância de construir um sistema de saúde pautado pelos princípios da universalidade, integralidade e eqüidade com organização descentralizada, regionalizada, hierarquizada e submetida ao controle pela sociedade civil.

Assim, apesar de a Abrasco ter tido apenas oito delegados representando-a formalmente na conferência, certamente sua influência nos resultados ultrapassou em muito essa participação. Muitos dos palestrantes convidados, coordenadores e relatores dos grupos temáticos, bem como o presidente Sérgio Arouca, o coordenador da plenária final, Arlindo Fábio Gómez de Sousa, e o relator-geral, Guilherme Rodrigues da Silva, eram parte da comunidade da associação.

A VIII Conferência Nacional de Saúde ocupa papel relevante na Reforma Sanitária brasileira por ter sido a primeira a contar com a participação organizada dos movimentos sociais. Até a quarta conferência, o fórum de debates era constituído exclusivamente pelos técnicos do setor. A partir da quinta, começam a ser incorporados docentes, pesquisadores, parlamentares e outros segmentos de representação, sem, entretanto, abrir para a participação de movimentos sociais. É em 1986, durante o primeiro governo civil, eleito ainda de maneira indireta pelo Congresso Nacional, após 22 anos de ditadura militar, que a oitava conferência é organizada. 
Esse é também o momento emblemático da apresentação da Abrasco como ator político cuja legitimidade é dada pela produção de conhecimentos originada em sua atuação acadêmica e pela capacidade de articulação de seus interesses aos dos demais movimentos sociais.

A atuação da Abrasco na formulação da política de saúde prossegue com a criação da Comissão Nacional da Reforma Sanitária e com o trabalho desenvolvido durante a Assembléia Nacional Constituinte para a elaboração do capítulo sobre a saúde.

Ainda em 1986, após a realização da VIII Conferência Nacional de Saúde, a diretoria realizou o I Congresso Brasileiro de Saúde Coletiva, no Rio de Janeiro, contando com cerca de dois mil participantes. Além das atividades acadêmicas e científicas, o congresso discutiu a Política Nacional de Saúde e em sua plenária final foi aprovado o texto elaborado por Eleutério Rodriguez Neto com base nas conclusões da conferência. Este texto balizou a atuação da Abrasco com relação à elaboração da nova Constituição do país. O texto aprovado contém seis artigos nos quais estão definidos: o direito à saúde, o dever do Estado, as ações intersetoriais, o caráter público das ações de saúde, a criação do Sistema Nacional de Saúde, o financiamento para o setor e a formulação de um plano nacional de saúde plurianual.

A Comissão Nacional da Reforma Sanitária tomou como base para seu trabalho esse texto aprovado pelo Congresso de Saúde Coletiva. Com a criação da Plenária Nacional de Entidades de Saúde, na qual a Abrasco mantém participação importante, a proposta passou a receber uma série de modificações e aprimoramentos.

Paralelamente ao trabalho no campo político, a Abrasco continuou desenvolvendo atividades de fortalecimento do campo acadêmico. No período entre sua criação, em dezembro de 1979, e o momento da Assembléia Nacional Constituinte foram criados vinte novos programas de residência em medicina preventiva e social no país, e os cursos de mestrado e doutorado também começaram a ser oferecidos fora do eixo Rio-São Paulo.

Nessa conjuntura há uma articulação quase perfeita entre a práxis política, a prática na direção de instituições de saúde, a produção acadêmica e a formação de quadros. Além do ex-presidente Hésio Cordeiro, naquele momento na presidência do Inamps, vários associados da Abrasco assumiram postos em secretarias estaduais e municipais de Saúde, alimentando com suas experiências concretas de gestão a reflexão teórica, técnica e política no interior da associação.

Assim, com o passar dos anos, a Abrasco vai concretizando os objetivos explicitados em sua criação: no campo acadêmico, a construção 
teórica do próprio campo. e o fortalecimento da produção científica; no campo profissional, a formação e capacitação dos profissionais e a gestão de organizações de saúde; no campo político, a constituição de um movimento social legitimado por outros parceiros da sociedade civil e a intervenção qualificada na formulação da Política Nacional de Saúde.

Ainda que nessa etapa o primeiro objetivo não estivesse tão desenvolvido quanto os demais, a Sociedade Brasileira para o Progresso da Ciência (SBPC) passou a reconhecer a Abrasco como uma das entidades científicas que compõem o seu conselho e também a solicitar a participação dela na organização de suas reuniões anuais.

Para o biênio 1987-1989, a diretoria eleita foi composta por Guilherme Rodrigues da Silva, Eleutério Rodriguez Neto, Luiz Cordoni Junior, Roseni Rosângela Chomprè e Paulo Buss. O presidente Guilherme Rodrigues da Silva era o chefe do Departamento de Medicina Preventiva da Faculdade de Medicina, onde exercia funções docentes no programa de pósgraduação e desenvolvia atividades de pesquisa na área de epidemiologia das doenças transmissíveis, além de ser um dos teóricos da formulação do próprio campo. Como alguns dos presidentes que o antecederam, sua formação clínica inicial na área da medicina tropical foi complementada por formação pós-graduada na área da Saúde Pública, realizada na escola de Saúde Pública da Universidade de Harvard e na própria USP.

Do mesmo modo que a diretoria anterior, essa dedicou a maioria de seus esforços ao trabalho na Assembléia Nacional Constituinte e à elaboração da Lei Orgânica da Saúde. Durante os trabalhos da Assembléia Nacional Constituinte, os membros da Abrasco, principalmente sua comissão de políticas de saúde e parte da diretoria, atuaram vigorosamente no seio do movimento sanitário, assessorando, no Congresso Nacional, a Comissão da Ordem Social e a Subcomissão de Saúde na elaboração do texto constitucional. Além dos subsídios originados na VIII Conferência e no seu primeiro congresso, a associação produziu análises de situação com base na avaliação da experiência do Sistema Unificado e Descentralizado de Saúde (Suds) implementado pelo Inamps, sob a presidência de Hésio Cordeiro.

Pelo Boletim Abrasco, os associados já podem acompanhar os movimentos e as proposições dos diferentes blocos de interesses que vão sendo constituídos ao longo dos trabalhos constituintes. No processo surgem divergências políticas e ideológicas inclusive entre a associação e a Comissão Nacional de Reforma Sanitária, que são explicitadas nos editoriais e artigos do Boletim. Dentre as propostas em pauta, a Abrasco opta pela proposta da Comissão de Sistematização, ainda que ela não contemple 
todas as propostas do movimento sanitário consubstanciadas na emenda popular encaminhada pela Plenária da Saúde. Esta é a proposta vitoriosa no plenário.

Nesse período, dois novos atores políticos importantes para o campo de formulação da política de saúde se constituem: o Conselho Nacional de Secretários de Saúde (Conass) e o Conselho Nacional de Secretários Municipais de Saúde (Conasems).

A aprovação da nova Constituição desloca o foco da atuação política para a formulação e a aprovação da Lei Orgânica da Saúde, fundamental para a concretização dos avanços obtidos. A atuação política da Abrasco no parlamento se traduz também na participação no VI Simpósio sobre Política Nacional de Saúde da Câmara.

No campo acadêmico, várias iniciativas são desenvolvidas objetivando, de um lado, a reflexão teórica sobre os desafios postos pela concepção do Sistema Único de Saúde e por sua efetivação e, de outro, o fortalecimento da produção científica na área.

Além dos seminários temáticos, merecem destaque: as tentativas de articulação de projetos multicêntricos, entre a Abrasco e as agências de fomento à pesquisa, buscando possibilitar o envolvimento do maior número possível de sócios institucionais em atividades de pesquisa voltadas para as grandes questões nacionais no campo da saúde; e a formulação do primeiro Plano Diretor para o Desenvolvimento da Epidemiologia no Brasil, iniciativa mobilizadora que desempenhou papel fundamental no fortalecimento dessa área e cujos desdobramentos na década de 90 são marcantes.

Para finalizar o trabalho dessa gestão, é realizado o II Congresso Brasileiro de Saúde Coletiva juntamente com o III Congresso Paulista de Saúde Pública. Como não poderia deixar de ser, o tema do congresso é "Sistema Único de Saúde: uma conquista da sociedade". Cerca de 2.500 participantes de todo o país se reúnem no campus da USP para discutir os vários aspectos a serem tratados na Lei Orgânica da Saúde.

Com a proximidade das primeiras eleições diretas para presidente da República após a ditadura, a questão da sucessão ganha espaço nas atividades do congresso, buscando não apenas apresentar aos candidatos as propostas do movimento sanitário, mas também comprometê-los com esse ideário. Entretanto, os resultados da eleição não foram promissores para o campo.

Após dez anos de criação, a Abrasco enfrenta talvez seu momento mais difícil durante os anos iniciais do governo Collor. A nova diretoria, 
eleita no II Congresso, enfrenta uma dura luta pela sobrevivência da instituição.

A diretoria eleita é composta por José da Silva Guedes, Nilson do Rosário Costa, Carmem Fontes Teixeira, Alina Maria Almeida de Souza e Péricles Silveira da Costa, este último em substituição a Paulo Buss na secretaria executiva. O presidente José da Silva Guedes, professor titular e chefe do Departamento de Medicina Social da Faculdade de Ciências Médicas da Santa Casa de São Paulo, aliava experiência docente, produção científica no campo da epidemiologia e experiência de gestão cono secretário municipal de Saúde da cidade de São Paulo, já no período de redemocratização. Mais uma vez, o presidente da entidade corporificava em sua trajetória profissional as múltiplas dimensões que são objeto de atuação da Abrasco. No final do mandato, como já havia acontecido com presidentes anteriores, Guedes assumiu a presidência do Instituto Nacional de Assistência Médica da Previdência Social, já integrado à estrutura do Ministério da Saúde, nessa fase inicial de implementação do SUS. Ao deixar o ministério, assumiria por oito anos a Secretaria de Estado da Saúde de São Paulo nos dois mandatos do governador Mário Covas.

O movimento sanitário, que vinha se fortalecendo desde a realização da VIII Conferência Nacional de Saúde, passa a enfrentar os efeitos negativos do projeto neoliberal do governo Collor sobre as políticas sociais em geral. A conjuntura é marcada por diversos elementos contraditórios. De um lado, registram-se avanços importantes como a aprovação da nova Constituição em 1988 e da Lei Orgânica da Saúde, as quais forneciam o arcabouço legal necessário para a implementação do Sistema Único de Saúde; e a instalação do Conselho Nacional de Saúde, em cumprimento à Lei 8.162 , possibilitando pela primeira vez na história do país a participação organizada da sociedade civil na formulação da Política Nacional de Saúde. Por outro lado, há a redução do financiamento da saúde e as medidas de desestruturação do setor público atingindo todas as áreas de atuação do Estado, com forte repercussão sobre as políticas públicas.

A instalação do Conselho Nacional de Saúde e a negociação com a SBPC para que a Abrasco pudesse exercer a representação da comunidade científica nesse conselho significaram nova oportunidade de inserção política para a associação, estreitamente relacionada ao acompanhamento da Política Nacional de Saúde. Além disso, o CNS constituiu-se em arena para a articulação política entre a Abrasco e os outros atores relevantes para a formulação, a implementação e o acompanhamento da política de saúde, propiciando maior visibilidade ao trabalho desenvolvido pela associação. 
Ainda no campo da atuação política, vale destacar a participação ativa da Comissão de Epidemiologia da Abrasco no processo de criação do Centro Nacional de Epidemiologia (Cenepi) pelo Ministério da Saúde, antiga reivindicação da comunidade de sanitaristas.

Durante essa gestão foi realizado o I Congresso Brasileiro de Epidemiologia, reunindo em Campinas (SP) cerca de 1.500 participantes e com a apresentação de trezentos trabalhos. A decisão sobre a realização do congresso de epidemiologia foi fruto de muita discussão entre a diretoria e os membros da Comissão de Epidemiologia, com importante participação da Organização Pan-Americana da Saúde no encaminhamento da proposta e na sua concretização. O principal receio de parte da diretoria e também do grupo de epidemiologistas era que a realização do congresso fosse vista como um anseio de autonomia da disciplina em relação ao campo. A maior preocupação na organização deste e dos demais congressos de epidemiologia foi sempre assegurar a ligação intrínseca dessa disciplina com a Saúde Coletiva.

Arlindo Fábio Gómez de Sousa foi o sexto presidente da Abrasco. Sua diretoria, eleita para o biênio 1991-1993, foi composta por Maria Cristina Lodi Guedes de Mendonça, José da Rocha Carvalheiro, Júlio S. Müller Neto e Péricles Silveira da Costa. O momento era particularmente delicado para a Saúde Coletiva no país e também para sua associação. O agravamento da crise política e institucional que resultaria no impeachment do presidente eleito e os efeitos das políticas neoliberais adotadas pelo governo eram fortemente sentidos no setor saúde, seja pelo agravamento do quadro sanitário, seja pelo enfraquecimento e pela desarticulação do aparelho de Estado.

Assim, a gestão da sexta diretoria da Abrasco transcorreu em meio a muita mobilização da associação para evitar que as conquistas que haviam sido alcançadas com a aprovação da Constituição Brasileira de 1988 e da Lei Orgânica da Saúde em 1990 não se perdessem completamente. Talvez essa tenha sido a diretoria cuja gestão foi marcada pela realização do maior número de seminários, encontros e congressos, espaços todos eles destinados à discussão e à organização da resistência do movimento sanitário.

Não se poderia esperar menos de um presidente com o perfil de Arlindo. Sua trajetória pessoal estava associada desde sempre a numerosas realizações na área de informação, educação e comunicação em saúde, assim como à intensa participação em todos os momentos importantes do movimento da Reforma Sanitária.

Participando da gestão de Antônio Sérgio Arouca à frente da Fundação Oswaldo Cruz, logo após o encerramento da ditadura militar, 
Arlindo havia se envolvido diretamente na criação da Escola Politécnica de Saúde Joaquim Venâncio, destinada a formar técnicos para o sistema de saúde que se sonhava construir; na concepção da Casa de Oswaldo Cruz como unidade destinada à recuperação e ao registro da história da Saúde Pública brasileira; no lançamento dos Cadernos de Saúde Pública, periódico científico fundamental para o campo no país.

Em 1986, lá estava ele dirigindo a assembléia final da VIII Conferência Nacional de Saúde que, sob a presidência de Sérgio Arouca, se constituiria no marco fundador do processo da Reforma Sanitária brasileira. Em seguida, tornou-se o coordenador da secretaria técnica da Comissão Nacional da Reforma Sanitária, participando decisivamente na elaboração das propostas de redação do capítulo sobre a saúde na Constituição brasileira e também da proposta de lei orgânica de criação do Sistema Único de Saúde. Era, portanto, natural que se tornasse o presidente da Abrasco justamente no momento mais crucial para a concretização das aspirações do movimento da Saúde Coletiva no Brasil. Fazer do SUS uma realidade era a tarefa mais urgente.

No início do mandato, a primeira providência foi tentar recuperar a representação no Conselho Nacional de Saúde, pois o presidente da SBPC havia indicado uma outra sociedade científica para a vaga. A presença da Abrasco nesse órgão de controle social da Política Nacional de Saúde adquiria ainda maior importância, dadas as características da conjuntura política. Recuperada a representação, com a interveniência do vicepresidente José da Rocha Carvalheiro, a luta passou a ser pela convocação da IX Conferência Nacional de Saúde, que deveria ter ocorrido em 1990. Somente após a troca de ministro da Saúde foi possível convocar a conferência, ainda que com dois anos de atraso.

Já em 1991, ao presidir o III Congresso Brasileiro de Saúde Coletiva em Porto Alegre (RS), imprimiu ao evento características muito coerentes com essa trajetória pessoal. O congresso foi pensado menos como um evento científico e mais como um local de convergência para todo tipo de manifestação social em torno da questão saúde. O lema "Saúde como direito à vida" pretendia a um tempo convocar a sociedade toda para a defesa desse direito e, a outro, agrupar em torno de si as mais diversas expressões de vitalidade presentes na sociedade brasileira. A Reforma Sanitária e a criação do SUS ocupavam o lugar central na agenda política, constituindo assim um ensaio geral para a conferência nacional, finalmente convocada para alguns meses após o congresso.

Além de participar da comissão organizadora, a Abrasco ficou encarregada dos trabalhos de relatoria, sendo seu presidente o relator-geral. 
Para apoiar os debates, a associação elaborou o documento "Saúde é qualidade de vida", abordando aspectos centrais para a instalação do SUS: financiamento do setor, relação público/privado, co-participação dos usuários no custeio do sistema, atribuições das esferas municipais, estaduais e federal, pessoal para a saúde e ciência e tecnologia em saúde.

Ainda em 1992, a diretoria, apoiada no trabalho da Comissão de Epidemiologia, realizou o II Congresso Brasileiro de Epidemiologia, em Belo Horizonte (MG), retomando mais uma vez o tema da qualidade de vida. Com todas as dificuldades financeiras vividas pela associação nesse período, o espírito inquieto e empreendedor do presidente, bem como dos demais membros da diretoria, não permitiu que as atividades aglutinadoras da comunidade acadêmica e de serviços do campo da Saúde Coletiva deixassem de ser realizadas. No ano seguinte, foi a vez da organização do I Encontro de Ciências Sociais em Saúde.

No final do mandato, a diretoria ainda teve fôlego para realizar o IV Congresso Brasileiro de Saúde Coletiva, em Olinda (PE), sob o lema "O feito por fazer", que adotamos para nomear este capítulo. As conotações embutidas no título são muitas, mas as principais remetem para o alerta de que o muito que já se havia conquistado no campo da Reforma Sanitária, em vez de permitir o acomodamento, convidava ao trabalho renovado e necessário diante do muito que ainda havia por fazer. Numa única frase se articulavam os ganhos e os desafios para o campo e para o movimento social do qual a Abrasco era parte atuante.

Com uma pobreza franciscana que levou, entre outras coisas, à impressão do programa em formato de papel jornal, a capacidade convocatória da Abrasco foi posta à prova, pois além da conjuntura bastante adversa, sem que ninguém tivesse se dado conta a abertura foi marcada para o horário da estréia do selecionado brasileiro na Copa do Mundo de futebol. Não houve outro jeito senão antecipar a cerimônia de abertura e providenciar telões para que os cerca de 3.800 participantes pudessem assistir ao jogo Brasil e Rússia no próprio centro de convenções. Nada poderia ter mais a feição do presidente e de sua diretoria.

Cumprida a missão de conduzir a associação durante esses anos de dificuldades que se somavam àqueles vividos pela diretoria anterior, Arlindo retoma suas numerosas atividades na Fundação Oswaldo Cruz e empenha-se em criar o Canal Saúde, respondendo a deliberações das conferências nacionais que reiteravam a necessidade de contar com recursos de comunicação social apropriados para o exercício da cidadania. Desde 1994, o Canal Saúde tem produzido e veiculado material audiovisual para atender a demandas específicas dos profissionais de saúde que constituem 
a maioria do seu público. Conselhos de saúde, escolas, associações e sindicatos também se utilizam dessa programação como veículo privilegiado. O trabalho que passou a ser desenvolvido pelo canal na cobertura dos congressos da Abrasco e das conferências nacionais de saúde tem possibilitado a ampliação da participação, pois leva através da televisão os debates a um número maior de profissionais de saúde e cidadãos. Para além de uma tarefa de educação continuada e a distância, compartida com as redes de TV Educativa, o Canal Saúde leva o movimento social pela saúde - movimento do qual faz parte, alimentando e sendo alimentado para a sala dos brasileiros. Em 2006 na chefia de gabinete da presidência da Fiocruz, Arlindo segue contribuindo, como sempre, para o alcance dos objetivos da Reforma Sanitária brasileira.

A etapa seguinte na história da associação e de seus presidentes sofreria uma inflexão refletindo as modificações na conjuntura política e a construção paulatina do Sistema Único de Saúde. Passadas as turbulências do primeiro governo eleito, após a ditadura, e as etapas iniciais da implementação do SUS, há como que uma necessidade de retomar de maneira mais decisiva a produção de conhecimentos para apoiar esse processo. É nesse contexto que a porção mais acadêmica da associação, relacionada com a formação de pesquisadores e a produção de conhecimentos científicos aplicáveis ao campo da política de saúde, parece ganhar relevância. Vencidas as primeiras batalhas, a necessidade de demonstrar a competência e a capacidade técnica para concretizar as propostas políticas impõe à associação um novo rumo: o fortalecimento da pós-graduação e da produção científica.

Maria Cecília de Sousa Minayo, juntamente com Marilisa Berti de Azevedo Barros, Renato Peixoto Veras, Pedro Miguel dos Santos Neto, Péricles Silveira da Costa e João Carlos Canossa Mendes, iria conduzir esse processo de fortalecimento acadêmico sem, entretanto, descuidar da participação da associação nas definições da Política Nacional de Saúde.

Cecília Minayo, docente da Escola Nacional de Saúde Pública e pesquisadora respeitada no campo por suas importantes contribuições, tinha o perfil apropriado para conduzir a associação nessa nova etapa. Sua experiência na coordenação do Programa de Pós-Graduação da ENSP foi bastante útil tanto para a representação de área na Comissão de Aperfeiçoamento de Pessoal de Nível Superior (Capes) quanto para alavancar os programas no país em geral.

A necessidade de fortalecimento da pós-graduação em Saúde Coletiva respondia a dois tipos de problemas: de um lado, a já mencionada necessidade de produzir novos conhecimentos que embasassem a 
implementação do Sistema Único de Saúde, e de outro o questionamento, mais ou menos velado, do caráter científico do campo. Todas as vezes que se solicitava apoio dos órgãos de fomento para a realização de atividades da associação, e mesmo nos embates por recursos para pesquisas e bolsas, voltava o questionamento acerca do seu caráter científico e de sua natureza predominantemente política no campo. Um dos episódios que trouxeram mais uma vez à tona esses questionamentos, logo no início do mandato da nova diretoria, foi a tentativa do Conselho Nacional de Desenvolvimento Científico e Tecnológico (CNPq) de impor como coordenador do comitê assessor um pesquisador da área de bioquímica de alimentos. Obviamente, a mobilização da comunidade não permitiu que a tentativa se concretizasse; entretanto, não houve força suficiente para garantir o nome escolhido pela própria comunidade.

Diante dessa conjuntura, a estratégia traçada pela presidente e por sua diretoria privilegiou a inserção da Abrasco na comunidade científica nacional seja na assembléia das sociedades científicas na SBPC, seja na representação junto aos órgãos de fomento. A participação ativa da associação na organização da I Conferência Nacional de Ciência e Tecnologia em Saúde fez parte dessa estratégia.

No âmbito do CNPq, a associação passou a organizar de modo mais sistemático o processo de indicação de membros para o comitê assessor, garantindo maior organicidade à representação. Ao mesmo tempo foram promovidos seminários para discutir critérios para auxiliar no julgamento dos pedidos de bolsas e financiamentos a projetos, de modo a preservar os recursos destinados à Saúde Coletiva para pesquisadores realmente do campo.

A maior fonte de tensão deu-se no âmbito da avaliação dos cursos de pós-graduação estrito senso e originou-se especialmente da área médica. Embora a Capes outorgue a cada área liberdade para estabelecer seus próprios critérios de avaliação, respeitando assim as especificidades de cada campo científico, na grande área da saúde a hegemonia dos representantes das áreas médicas (Medicina I, II e III) sempre motivou atitudes preconceituosas, fruto do desconhecimento em relação à Saúde Coletiva.

Portanto, realizar uma avaliação independente dos programas da área tornou-se uma tarefa prioritária. Assim, vários docentes foram envolvidos na elaboração de estudos sobre tópicos específicos, produzindo material para a realização da avaliação. É importante destacar que até esse momento o processo de avaliação implantado pela Capes em 1976 não tinha definição clara de indicadores, sendo bastante subjetivo e estando sujeito muitas vezes ao conhecimento ou desconhecimento dos representantes de área a respeito de cada um dos programas avaliados. 
Para dar caráter independente à avaliação, a diretoria comandada por Cecília convidou dois pesquisadores estrangeiros para realizá-la: Sherman James, da Universidade de Michigan (EUA), e Claudine Herzlich, do Institut National de la Santé et de la Recherche Médicale/Inserm (França). A partir desse trabalho, foi possível desfazer uma série de equívocos e prenoções que havia na própria comunidade da Saúde Coletiva e também no restante da comunidade científica da área da saúde, demonstrando que a produção científica e intelectual do campo era inclusive superior àquela verificada na área médica.

Como desdobramento desse esforço, a diretoria instituiu o Fórum de Coordenadores dos Programas de Pós-Graduação em Saúde Coletiva, que permanece ativo, como instância de formulação de propostas para a pós-graduação senso estrito e reflexão sobre a formação de pesquisadores, além de base concreta para a representação da área junto à Capes. Sem dúvida, esse é um diferencial de organização do campo que contribuiu para modificar substancialmente a posição da Abrasco na interlocução nesse âmbito, transformando-a em ator efetivo no processo de fortalecimento da pós-graduação no país.

Outro desdobramento significativo foi a criação da revista Ciência \& Saúde Coletiva como periódico científico da Abrasco, definindo um perfil próprio por referência às outras revistas já existentes no campo. A opção da diretoria foi criar uma revista temática, tendo em vista a necessidade de organizar a produção sobre a Saúde Coletiva de acordo com suas temáticas, dando visibilidade e limites mais claros ao campo. Seus primeiros números foram dedicados à publicação dos produtos resultantes da avaliação dos programas de pós-graduação e à veiculação de reflexões sobre as diferentes áreas temáticas produzidas pelas comissões e pelos grupos de trabalho da associação.

Articulada à necessidade de divulgação da produção científica, além da criação da revista Ciência \& Saúde Coletiva, foi proposta a criação da livraria da Abrasco, mecanismo não apenas de arrecadação, mas principalmente de difusão de parte significativa da produção intelectual do próprio campo e de autores afins, brasileiros e estrangeiros.

Sob a presidência de Cecília Minayo foram realizados o III Congresso Brasileiro de Epidemiologia e o I Congresso de Ciências Sociais em Saúde, ambos em 1995, dando continuidade aos eventos científicos. O III Congresso Brasileiro de Epidemiologia propiciou à Abrasco a oportunidade de se integrar à Asociación Latinoamericana de Medicina Social (Alames) e à Sociedade Ibero-Americana de Epidemiologia na promoção de evento científico de caráter internacional. Estiveram presentes cerca de 3.500 pessoas 
oriundas de 22 países. O I Congresso de Ciências Sociais em Saúde também reuniu um número expressivo de participantes, dando início a uma nova série de congressos que veio se somar aos de epidemiologia e Saúde Coletiva. Ainda em 1995, a associação organizou o Seminário LatinoAmericano sobre condições de vida e situação de saúde, com participação de pesquisadores da América Latina e convidados da Espanha.

A atuação política da Abrasco no Conselho Nacional de Saúde continuou a ser intensa, destacando-se a elaboração da Norma Operacional Básica (NOB 96) em colaboração com o Conselho Nacional de Secretários de Saúde (Conass) e o Conselho Nacional de Secretários Municipais de Saúde (Conasems). A Abrasco, como de outras vezes, integrou a comissão de organização da X Conferência Nacional de Saúde, contribuindo ainda na elaboração de um boletim dedicado à pauta do evento. Novos atores políticos surgidos no processo de redemocratização do país ou fortalecidos por ele permitiram à associação definir de modo mais claro seu papel na arena política: o aporte de uma associação científica cujo objeto de reflexão e produção científica é a condição de saúde da população e as políticas sociais em saúde.

A próxima diretoria daria continuidade ao trabalho iniciado por Cecília Minayo, procurando consolidar a presença da Abrasco na comunidade científica nacional e internacional. Ela foi composta por Rita Barradas Barata na presidência, Eduardo Stotz, Everardo Duarte Nunes, Elizabeth Diniz Barros, Mário Dal Poz, Oswaldo Yoshimi Tanaka e Péricles Silveira da Costa. Esta diretoria apresentou algumas particularidades, tais como a expansão do número de membros da diretoria, decorrentes das mudanças regimentais realizadas no final da gestão anterior, e o prolongamento de mandato devido a dois fatos: o adiamento do V Congresso Brasileiro de Saúde Coletiva provocado pela realização da X Conferência Nacional de Saúde, agendada para o mesmo período, e a tentativa de fazer coincidir a posse da nova diretoria com a realização do 'Abrascão', isto é, o Congresso Brasileiro de Saúde Coletiva. Assim, a gestão durou quatro anos, de 1997 a 2000.

Rita Barradas Barata era então docente do Departamento de Medicina Social da Faculdade de Ciências Médicas da Santa Casa de São Paulo, tendo sua atividade principal na área da epidemiologia de doenças transmissíveis e no estudo das desigualdades sociais em saúde. Seu perfil profissional, assim como o de Cecília Minayo, estava dirigido para a docência e a pesquisa.

Dando seguimento ao trabalho que vinha sendo realizado pela associação no campo da pós-graduação em Saúde Coletiva, a atuação junto 
à Capes, por intermédio do representante de área, Maurício Barreto, atingiu um novo patamar com a participação no Conselho Técnico Consultivo. A grande área da saúde tradicionalmente participava com um dos representantes da área médica, sendo pela primeira vez representada pela Saúde Coletiva. A formulação de critérios objetivos de avaliação, que já vinha sendo impulsionada, ganhou maior consistência, e teve início um processo controvertido de classificação dos periódicos científicos. No campo da Saúde Coletiva, todos estes aspectos foram amplamente discutidos pelo Fórum de Coordenadores dos programas, aportando diversas contribuições no sentido do aprimoramento do processo.

Ainda no âmbito da formação, teve início na etapa de representação junto à Capes feita por Moisés Goldbaum, que substituiu Maurício Barreto, a discussão dos mestrados profissionais como forma de qualificação do pessoal da saúde. Os primeiros programas só seriam oferecidos após o ano 2000.

$\mathrm{O}$ comitê assessor do CNPq também trabalhou bastante articulado com a diretoria, permitindo que a atuação nessa área fosse balizada pelas discussões da política científica e tecnológica traçada pela associação. Ainda no campo do fomento à pesquisa, a associação teve participação importante na criação do Departamento de Ciência e Tecnologia (Decit) na Secretaria de Políticas de Saúde do Ministério da Saúde, respondendo a uma antiga demanda da comunidade.

A inserção da associação na SBPC também mudou de patamar, com a participação ativa na elaboração da programação central da $52^{\mathrm{a}}$ reunião, além da participação setorial que já vinha se dando em momentos anteriores.

Logo no início da gestão, em 1997, foi realizado o V Congresso Brasileiro de Saúde Coletiva, retomando a questão da responsabilidade do Estado na garantia do direito à saúde. Sentiu-se a necessidade de reafirmar esse princípio exatamente como conseqüência dos efeitos negativos da política econômica sobre a saúde e da escassez de verbas para o setor. O congresso procurou discutir e agregar elementos de acúmulo político para a luta pela aprovação da emenda constitucional referente à vinculação de recursos orçamentários para a saúde.

Em 1998 ocorreu o IV Congresso Brasileiro de Epidemiologia, reunindo cerca de 2.200 participantes, no Rio de Janeiro, e em 1999 a associação realizou outros três eventos importantes: o II Congresso Brasileiro de Ciências Sociais em Saúde, o I Encontro Latino-Americano em Saúde, Equidade e Gênero, juntamente com a Alames, e o I Congresso Internacional Mulher, Trabalho e Saúde, reunindo delegações de países dos cinco continentes. 
Dentro do projeto editorial da Abrasco, foi criada em 1997 a Revista Brasileira de Epidemiologia, para acolher parte da produção crescente nessa área, decorrente por um lado da ampliação dos programas de pós-graduação estrito senso, e por outro do enorme esforço de capacitação em epidemiologia dos profissionais de saúde, desenvolvido tanto pelo Ministério da Saúde, especialmente pelo Cenepi, quanto por estados e municípios, contando sempre com a participação dos sócios institucionais da Abrasco na realização de cursos de especialização e capacitação em todo o país.

Essa diretoria também concretizou a primeira parceria internacional da Abrasco, com a Associação Canadense de Saúde Pública (CPHA), para estimular o intercâmbio de experiências em promoção da saúde. Tal parceria foi concretizada contando ainda com a interveniência das agências de cooperação internacional de ambos os países.

Ao lado da atividade acadêmica, a Abrasco intensificou sua participação nas comissões intersetoriais do Conselho Nacional de Saúde, estando presente na Comissão Intersetorial de Ciência e Tecnologia, na Comissão Intersetorial de Saúde da Mulher, na Comissão Intersetorial de Saúde e Trabalho e na Plenária de Recursos Humanos em Saúde. Mediante um convênio firmado com a secretaria executiva do Conselho Nacional de Saúde, a Abrasco viabilizou ainda a produção de revistas para a Comissão de Ética em Pesquisa com Seres Humanos e a elaboração de produtos técnicos para o embasamento da atuação do CNS.

Ainda no campo das políticas de saúde, a atuação do Grupo Temático em Informação, Saúde e População (GTISP) na Rede Interagencial de Informação, População e Saúde (RIPSA) foi bastante destacada no período. Esta atuação também foi bastante relevante na comissão encarregada de elaborar o suplemento de saúde para a Pesquisa Nacional por Amostra de Domicílios (PNAD) 1998, bem como na análise dos dados gerados.

O trabalho realizado a partir da Comissão Intersetorial de Ciência e Tecnologia em articulação com o Decit resultou na formulação de uma proposta para a Política Nacional de Ciência, Tecnologia e Inovação em Saúde, que seria posteriormente aprovada na II Conferência Nacional de Ciência e Tecnologia em Saúde.

Finalizando a gestão dessa diretoria, foi realizado o VI Congresso Brasileiro de Saúde Coletiva, em Salvador (BA), com mais de cinco mil participantes discutindo o tema central: "O sujeito da Saúde Coletiva". Talvez de maneira mais clara do que nos anteriores congressos da associação, este dividiu o espaço central de sua programação entre as questões políticas 
de relevância para a Política Nacional de Saúde com as questões políticas relevantes para o trabalho acadêmico e para a produção de conhecimentos no campo.

Como decorrência do trabalho da Abrasco no Conselho Nacional de Saúde, Rita Barradas Barata foi indicada para coordenar a XI Conferência Nacional de Saúde, tendo Elizabeth Barros, também da diretoria, como relatora-geral. Toda a comunidade da associação envolveu-se ativamente nos trabalhos preparatórios, elaborando documentos básicos para embasamento dos debates, participando em mesas-redondas e painéis nas conferências estaduais e também na conferência nacional. Se desde a VIII Conferência a participação da Abrasco havia sido importante, na XI ela foi central. Como fez em relação às conferências anteriores, a associação elaborou um documento para balizar sua atuação, já a cargo da nova diretoria que havia sido empossada em Salvador.

A nona diretoria a assumir a condução dos trabalhos da Abrasco foi composta por José Carvalho de Noronha como presidente e Francisco Eduardo de Campos, Jairnilson Paim, Márcia Furquim de Almeida, Paulo Mangeon Elias e Paulo Marchiori Buss como vice-presidentes, além de Álvaro Matida e Mônia Mariani na secretaria executiva.

José Carvalho de Noronha era então professor do Instituto de Medicina Social da Universidade do Estado do Rio de Janeiro (Uerj) e pesquisador do Centro de Informação e Comunicação em Saúde da Fiocruz. Aliava a experiência docente e de investigação na área de gestão e planejamento ao exercício de diversos cargos na administração pública, dentre os quais o de secretário de Saúde do Estado do Rio de Janeiro. Como a maioria dos presidentes da entidade, combinava o perfil acadêmico ao de gestor público.

Sua gestão foi marcada pela intenção de retomar o protagonismo político da Abrasco no campo da política de saúde, que uma parte dos associados supunha perdido pela inflexão mais acadêmica que havia caracterizado as duas últimas gestões.

Ainda que o trabalho político nunca tivesse sido abandonado, a maior ênfase colocada na organização e na consolidação da pós-graduação estrito senso e no reconhecimento da Abrasco como um interlocutor qualificado na comunidade científica brasileira era vivida por muitos como um certo desvio dos rumos que haviam marcado a associação, existindo inclusive, durante toda a gestão, a presença de uma tensão permanente entre aqueles que viam na Abrasco um movimento social e aqueles que a concebiam como associação científica do campo da Saúde Coletiva intrinsecamente relacionada com a formulação das políticas de saúde. 
O momento político no qual assumiu a nova diretoria era bastante diverso daquele existente em 1997. A gestão do ministro Serra à frente do Ministério da Saúde havia colocado a Política Nacional de Saúde na agenda política do país de forma relativamente inédita até então. A aprovação da Emenda Constitucional 29 significou um aporte maior de recursos para o setor, embora ainda insuficiente. No campo acadêmico e científico, a Abrasco era naquele momento um interlocutor importante, e a pós-graduação em Saúde Coletiva poderia ser considerada consolidada, havendo pelo menos alguns programas de excelência com inserção internacional.

Nos primeiros meses da sua gestão, Noronha, de maneira coerente com a plataforma apresentada, dedicou-se ao trabalho de articulação da Abrasco tendo em vista a realização da XI Conferência Nacional de Saúde. O documento "Atualizando a agenda da Reforma Sanitária brasileira", elaborado para embasar a participação dos delegados, destacava os pontos críticos para a organização do SUS: precarização das relações de trabalho, aceleração do processo de qualificação-desqualificação das relações técnicas do trabalho em saúde, dificuldades gerenciais, a criação de agências reguladoras e o potencial papel desagregador delas para o sistema, dicotomia entre atenção básica e integralidade da assistência, e a ausência de políticas de qualidade.

Também em consonância com a proposta de reafirmar o papel político da Abrasco, houve por parte da diretoria um cuidado especial em relação à inserção internacional da associação. Assim, a filiação da Abrasco à Federação Mundial de Associações de Saúde Pública (World Federation of Public Health Associations - WFPHA) foi um passo importante. A participação da associação no Global Forum for Health Research, com a apresentação de sua proposta para a Política de Ciência, Tecnologia e Inovação em Saúde, foi outro passo na direção da internacionalização. Além da participação em fóruns acadêmicos e políticos, a associação iria se envolver de maneira importante no processo sucessório na OMS.

Outra iniciativa sumamente importante no processo de internacionalização da associação foi a elaboração do documento de Saúde Pública internacional feito para apoiar as intervenções da delegação brasileira durante a reunião do Conselho Executivo da Organização Mundial da Saúde, em 2003.

A participação ativa do presidente na campanha eleitoral de 2002 e o posterior envolvimento com a equipe de transição também caracterizaram essa nova etapa de atuação mais política. Para a campanha, a associação, em parceria com o Centro Brasileiro de Estudos de Saúde (Cebes), elaborou o documento "Em defesa da saúde dos brasileiros". 
No âmbito interno à própria associação, as mudanças também foram perceptíveis, principalmente na ampliação dos grupos temáticos (criação de quatro GTs) e conseqüentemente na participação da Abrasco na organização de numerosos eventos.

$\mathrm{O}$ trabalho junto à Capes, ao $\mathrm{CNPq}$ e à $\mathrm{SBPC}$ seguiu da forma como vinha sendo feito nas gestões anteriores, consolidando ainda mais a presença da Abrasco na comunidade científica brasileira.

De fundamental importância não apenas para a Saúde Coletiva, mas para toda a pesquisa em saúde no país, foi a criação, em 2003, na gestão do ministro Humberto Costa, da Secretaria de Ciência, Tecnologia e Insumos Estratégicos no Ministério da Saúde e a nomeação de Reinaldo Guimarães para a direção do Decit. Estes dois fatos significaram um enorme fortalecimento da interlocução da saúde com as demais áreas científicas e principalmente o estabelecimento formal de relações entre a Política Nacional de Saúde e a Política Nacional de Ciência, Tecnologia e Inovação. $\mathrm{O}$ aporte incremental de recursos financeiros para a pesquisa em saúde também foi significativo, permitindo ao setor um novo patamar de produção.

Esses desdobramentos sem dúvida foram frutos também da atuação de Noronha como presidente da Abrasco na condução da Comissão Intersetorial de Ciência e Tecnologia (CICT) do Conselho Nacional de Saúde. O diálogo com outras sociedades científicas como a Federação das Sociedades de Biologia Experimental (Fesbe) e a Academia Brasileira de Ciências $(\mathrm{ABC})$ foi fundamental para estabelecer a aliança política capaz de apoiar essa antiga reivindicação.

Mais um dos indícios da importância crescente do campo da Saúde Coletiva na comunidade científica brasileira pôde ser visto na nomeação de Maurício Barreto e, mais recentemente, de César Victora como membros da Academia Brasileira de Ciências, que, apesar de ter tido Oswaldo Cruz como um de seus membros fundadores, não abrigou muitos sanitaristas ao longo de sua história mais recente.

Outra área de atuação fundamental para a Abrasco, a da formação e capacitação de profissionais de saúde, passou a ter na recém-criada Secretaria de Gestão do Trabalho em Saúde (Segest) um novo interlocutor, ampliando assim o campo de articulação e de atuação política da associação. Do mesmo modo que a Secretaria de Ciência, Tecnologia e Insumos Estratégicos, a Segest viria a ser comandada por um 'abrasquiano' histórico: Francisco Campos.

Assim, vê-se que a despeito da ênfase que em cada momento possa ser dada a um dos três eixos que desde o princípio compuseram as atividades da Abrasco, em cada um dos momentos marcados pela atuação 
das distintas diretorias, todos eles estão presentes: a formação, a pesquisa e a política de saúde.

A nona diretoria também se empenhou na realização de diversos eventos científicos desde o princípio de sua gestão. Já em 2001 foi organizado e realizado o II Encontro Nacional de Educação Popular e Saúde, retomando uma atividade que havia tido seu primeiro encontro na década de 80 . Nesse mesmo ano, a associação preparou um documento para a Conferência Nacional de Ciência, Tecnologia e Inovação, organizada pelo Ministério da Ciência e Tecnologia. Em 2002 foi a vez do V Congresso Brasileiro de Epidemiologia, realizado em Curitiba (PR), do II Seminário Nacional de Saúde e Ambiente e do Seminário de Ciências Humanas e Sociais em Saúde.

No seu último ano, as energias foram canalizadas para a realização do VII Congresso Brasileiro de Saúde Coletiva e para a organização da XII Conferência Nacional de Saúde, convocada antecipadamente para dezembro de 2003. O VII Congresso extrapolaria todas as previsões, reunindo cerca de 7.500 participantes, na Universidade de Brasília (UnB), sob o lema "Saúde, Justiça, Cidadania". Rememorando o IV Congresso, realizado em Porto Alegre (RS) em 1991, esse também foi marcado pela diversidade, inclusão e criatividade, mesclando em doses variadas as porções acadêmica, científica, política e de movimento social da Abrasco. Mais uma vez, o 'Abrascão' era a cara da sua diretoria.

Pela primeira vez na história da Abrasco, houve acirrada disputa em torno da composição da chapa que deveria apresentar-se às eleições para a décima diretoria. Entretanto, a diretoria sob a presidência de Noronha logrou construir o consenso entre os sócios institucionais de modo a que novamente houvesse apenas uma chapa postulando a aprovação dos associados. Naquele momento, mais uma vez, surgiu explicitamente a polarização entre o grupo que defendia uma atuação da Abrasco mais próxima à de um movimento social e o grupo que defendia o caráter de associação científica do campo da Saúde Coletiva como característica primordial.

Durante o VII Congresso foi empossada a décima diretoria, com mandato até 2006. Ela era constituída por Moisés Goldbaum na presidência, Paulo Ernani Vieira Gadelha, Júlio Strubling Müller Neto, Madel Therezinha Luz, Rômulo Maciel Filho e Soraya Cortes nas vice-presidências, e Álvaro Matida e Mônia Mariani na secretaria executiva.

Moisés Goldbaum era então docente do Departamento de Medicina Preventiva da Faculdade de Medicina da USP, com atuação em pesquisa na área de epidemiologia. Além de seu trabalho docente, sua 
trajetória profissional incluía a participação, como técnico, em agências de fomento à pesquisa, como o $\mathrm{CNPq}$, e organismos internacionais, como a Opas. Desde a constituição da Abrasco, ele havia atuado de maneira destacada na Comissão de Epidemiologia e na Comissão de Ciência e Tecnologia. Antes de assumir a presidência, exerceu a representação da área junto à Capes, tendo papel importante na manutenção das especificidades do campo nos critérios de avaliação propostos pela grande área da saúde. Ele era ainda o editor científico da Revista de Saúde Pública.

A plataforma dessa diretoria, como daquelas que a antecederam, afirmava a intenção de consolidar os avanços já obtidos e ampliá-los no que respeita à legitimação do campo entre a comunidade científica nacional e internacional, os órgãos de fomento à pesquisa e os formuladores e prestadores de serviços de saúde. As áreas de atuação continuavam sendo a geração de conhecimentos, a formação de recursos humanos e a formulação das políticas de saúde e ciência e tecnologia em saúde.

Uma das primeiras atividades da nova diretoria foi a realização do VI Congresso Brasileiro de Epidemiologia, que reuniu em Olinda (PE) cerca de quatro mil participantes. Em 2004, a Abrasco organizou o II Simpósio Brasileiro e o I Simpósio Pan-Americano de Vigilância Sanitária, dando continuidade às atividades nesta área, iniciadas pela diretoria anterior.

Ainda em 2004, a participação da Abrasco na II Conferência Nacional de Ciência, Tecnologia e Inovação em Saúde foi intensa, pois além de seu coordenador e a relatora adjunta serem membros da Comissão de Ciência e Tecnologia da Abrasco, diversos membros da associação estavam entre os delegados. O presidente Moisés Goldbaum, conselheiro do CNS, foi indicado para coordenar uma das plenárias finais. Além disso, a associação havia participado intensamente da elaboração do documento de política nacional e da formulação das agendas de prioridade em pesquisa, que estavam sendo debatidos na conferência.

Um dos pontos centrais defendidos pela associação era a criação de uma instância setorial de fomento à pesquisa em saúde para garantir fortalecimento da política científica e tecnológica em saúde, fluxo financeiro adequado e procedimentos administrativos coerentes com as características de fomento. Embora a criação do Decit tenha representado um avanço em relação à situação anterior, o fato de ele fazer parte da administração direta do Ministério da Saúde provocou uma série de entraves ao financiamento da pesquisa em saúde que uma agência de fomento não tem. Apesar do empenho da associação, a proposta foi derrotada, demonstrando até que ponto a compreensão das necessidades no campo da pesquisa está distante do cotidiano dos movimentos sociais representados na conferência. 
No final de 2004, a diretoria organizou um evento na sede da Organização Pan-Americana da Saúde em Brasília para comemorar os 25 anos de existência da Abrasco. Todos os ex-presidentes foram convidados a apresentar sua experiência na condução da associação, auxiliando assim no registro dessa história. O evento tratou ainda de projetar os desafios para o futuro.

No princípio de 2005, ocorreu um fato inédito na história da associação. Seu presidente foi convidado para assumir a Secretaria de Ciência e Tecnologia e Insumos Estratégicos do Ministério da Saúde estando em meio a seu mandato. Com muitos dos presidentes anteriores, havia ocorrido que após completar o mandato eles assumiram cargos na administração pública; entretanto, durante o mandato era a primeira vez. Com a aceitação do convite, Paulo Ernani Gadelha, um dos vice-presidentes eleitos, assumiu a condução da diretoria em substituição a Moisés Goldbaum.

Paulo Gadelha era pesquisador titular da Fundação Oswaldo Cruz e no momento ocupava a Vice-Presidência de Desenvolvimento Institucional e Gestão do Trabalho dessa instituição. Como sanitarista e pesquisador, tinha grande experiência no campo do planejamento e gestão. Sua trajetória profissional incluía a direção da Casa de Oswaldo Cruz, unidade da Fiocruz dedicada à memória, à história e à divulgação científica em saúde à qual está vinculado o Museu da Vida, que Gadelha idealizou e coordenou na fase inicial de implantação. O novo presidente daria seqüência ao programa traçado pela diretoria.

Em 2005, a Abrasco participou da Conferência Luso-Francófona em Saúde ocorrida em Montreal, no Canadá, dando prosseguimento à sua inserção internacional, e organizou o III Congresso de Ciências Humanas e Sociais em Saúde, na cidade de Florianópolis (SC). Mas a grande tarefa da diretoria passou a ser a realização do VIII Congresso Brasileiro de Saúde Coletiva e do XI Congresso Mundial de Saúde Pública, ocorrido no Rio de Janeiro em 2006, já no encerramento do mandato. O evento viria a coroar todos os esforços de inserção internacional da associação, reunindo cerca de 12 mil participantes provenientes dos mais diferentes países para discutir a "Saúde Coletiva em um mundo globalizado: rompendo barreiras sociais, econômicas e políticas". A Abrasco pôde demonstrar para os numerosos presidentes de associações de Saúde Pública ali presentes sua capacidade convocatória, sua expertise na organização de eventos científicos e principalmente a pujança da área no Brasil.

Este breve relato sobre os presidentes e suas diretorias ao longo desses 27 anos de história ilustra a trajetória da associação, tentando inserila no processo histórico mais geral da sociedade brasileira sem desconhecer 
as características peculiares que os sujeitos são capazes de imprimir aos processos que os sobrepassam. Para além das características pessoais de seus presidentes, a história da Abrasco é a história do desenvolvimento de um campo científico que, em seu processo de constituição, articulou-se intimamente com a história da política social de saúde do país. O protagonismo nesse movimento político foi em alguns momentos muito nítido e, em outros, cedeu passo à articulação com outros movimentos políticos e sociais sem, entretanto, perder a contribuição específica que um campo científico comprometido pode dar à concretização de uma política.

Cada um dos personagens aqui retratados e um número infinitamente maior de sujeitos, que em cada um dos momentos focalizados construíram essa história, foram capazes de imprimir suas características humanas peculiares, suas crenças, suas visões de mundo, suas maneiras de atuar, dando o colorido e o tempero a um processo histórico no qual são, a um só tempo, construtores e construídos.

\section{O POR FAZER}

Haverá sempre algo por fazer, por mais que algo já tenha sido feito, e não poderia ser diferente com a história da Abrasco. Retrospectivamente, como bem documenta este livro, muito já se fez, porém em uma associação viva sempre haverá muito por fazer.

No âmbito da formação profissional, o desafio que se apresenta é a contínua preparação de recursos humanos com capacidade técnica para identificar e hierarquizar as necessidades sociais em saúde; organizar saberes e instrumentos em modelos tecnológicos de trabalho que garantam a efetividade das intervenções e avaliar os impactos das intervenções adotadas. Além da capacidade técnica, os profissionais da Saúde Coletiva necessitam de capacidade para a negociação política interna e externa ao setor; capacidade para fazer a intermediação entre o conhecimento acadêmico e as práticas nos serviços de saúde; e capacidade para organizar as evidências científicas para embasar as funções regulatórias do Estado.

Para a formação acadêmica, os desafios que se apresentam são a transição necessária da produção de conhecimentos sobre a doença para a produção de conhecimentos sobre a saúde; a valorização da promoção da saúde; a ênfase na dimensão populacional e nos determinantes sociais, além da compreensão das características do Estado moderno em que as relações com a sociedade podem ser vistas como resultando de um contrato social entre cidadãos ativos e um Estado democrático aberto às reivin- 
dicações. As próprias ações de Saúde Pública hoje são executadas em um contexto no qual o direito à saúde está pensado como a garantia de direitos individuais e a limitação à ação estatal.

Os docentes e pesquisadores da área devem ser capazes de identificar problemas de pesquisa coerentes com as necessidades em saúde, apresentar sólida formação teórica e metodológica, capacidade de interação com pesquisadores de outros campos disciplinares, comportamento ético, capacidade de captação de recursos para a pesquisa, regularidade de publicação, liderança, capacidade de comunicação social com políticos, patrocinadores e com a comunidade e capacidade de formar novos pesquisadores.

Em relação à formação em Saúde Coletiva, a atuação da Abrasco pode ser dividida em dois âmbitos principais: a pós-graduação estrito senso e a lato senso. Para a pós-graduação lato senso, o desafio que se apresenta imediatamente para a associação é o papel que ela poderá vir a ter no processo de acreditação das instituições formadoras. A proposta de acreditação desenvolvida em parceria da Escola Nacional de Saúde Pública do Brasil com sua congênere francesa necessita de uma instituição como a Abrasco para sua legítima implementação. Em vez de realizar 'exames de especialistas', a exemplo da maioria das sociedades científicas da área da saúde, a Abrasco poderia avaliar a qualidade das instituições formadoras segundo parâmetros bem definidos. Dessa forma, seria possível estabelecer para a sociedade a sinalização necessária acerca das instituições competentes para a formação. A mercantilização crescente de todas as esferas de formação torna obrigatória a adoção de mecanismos de controle social pela própria comunidade, independentemente das ações que possam ser desenvolvidas pelo Ministério da Educação. Evidentemente, a legitimidade do processo decorrerá do consenso que poderá ser estabelecido entre os pares em torno das características dessa acreditação.

No campo da pós-graduação estrito senso, o fortalecimento do trabalho do Fórum de Coordenadores pode ser o instrumento para não apenas acompanhar os aspectos operativos dos programas de pósgraduação, mas para produzir reflexões, questionamentos e sugestões relacionados à política nacional de pós-graduação. Algumas tarefas se apresentam como imediatas nesse campo, dentre as quais podemos destacar a necessidade de aprimoramento e consolidação de diversos programas e contribuições para o processo de avaliação. Quanto ao aprimoramento e consolidação dos programas, a própria Capes, com as modificações propostas para os critérios de avaliação, abriu a possibilidade de valorizar o trabalho solidário entre programas. A Abrasco tem papel importante na 
organização dessa cooperação entre programas já consolidados e programas que apresentam algum grau de dificuldade.

Um segundo aspecto que poderá ser tomado como desafio pela associação é o aprimoramento dos critérios de avaliação tendo em vista o grande poder de indução que eles apresentam. Os critérios necessitam ser discutidos segundo a política científica e tecnológica para melhor atender aos interesses nacionais. A forma relativamente acrítica com que esses critérios têm sido estabelecidos acabam por induzir distorções no processo de formação. A Abrasco, por meio de sua comunidade de sócios individuais e coletivos, está em condição de oferecer propostas mais coerentes e comprometidas para o programa nacional de pós-graduação. Ainda com relação aos critérios de avaliação, há necessidade de produzir classificações mais apropriadas de periódicos científicos, livros e produções técnicas objetivando superar as insuficiências e inconsistências vigentes.

A Abrasco poderá também desempenhar papel destacado no estímulo à produção teórica e metodológica sobre os impactos produzidos pelo sistema de avaliação em seus aspectos positivos e negativos. Talvez seja o momento de voltar a produzir uma nova avaliação independentemente de seus programas, passados dez anos da primeira iniciativa.

O mestrado profissional, nova modalidade de pós-graduação estrito senso, tem apresentado forte expansão. Para os sócios institucionais da Abrasco, a demanda por oferta de mestrado profissional vem se avolumando nos últimos anos. Seria interessante promover alguma avaliação do impacto desses programas mediante a análise dos produtos gerados por eles. Outro aspecto importante no que se refere ao mestrado profissional é a necessidade de formulá-lo de modo bastante diferenciado em relação aos cursos de especialização, sob pena de que suas melhores possibilidades se percam no processo.

Contemplando a vocação que a associação tem demonstrado para a internacionalização de sua presença no campo da Saúde Coletiva, ela poderia articular, em parceria com seus associados, iniciativas de formação de pesquisadores para países latino-americanos e países africanos de língua portuguesa, não só com aqueles com o mesmo grau de desenvolvimento científico, mas principalmente com aqueles cujo patamar de desenvolvimento da produção científica em Saúde Coletiva é ainda incipiente. Essas iniciativas precisariam ter a marca da solidariedade e da cooperação para ampliar a capacidade da América Latina de pensar seus próprios problemas e encontrar suas próprias soluções.

Do mesmo modo que na área de formação, as exigências atuais para a política científica e tecnológica são amplas e variadas. Por um lado, 
o desenvolvimento da pesquisa estratégica com aplicação de seus produtos em benefício da saúde da população e, por outro, o desenvolvimento de processos técnicos capazes de transformar em produtos úteis os avanços alcançados pelas ciências básicas são exigências incontornáveis. Entretanto, a produção de corte mais acadêmico não poderá ser abandonada sob pena de que o campo sofra a esterilização teórica hoje tão presente em algumas áreas científicas. A produção de conhecimentos comprometida com a soberania nacional, a solução de problemas sociais relevantes, a qualidade e o mérito científico e a ética no seu desenvolvimento e na aplicação de seus produtos devem ser a aspiração da associação nesse âmbito.

A elaboração de um plano diretor para a ciência, tecnologia e inovação em Saúde Coletiva poderia representar um instrumento eficaz para balizar as atividades nesse âmbito. A elaboração desse instrumento não deve significar o desconhecimento das necessidades mais amplas da grande área da saúde como um todo. Entretanto, existem peculiaridades do campo da Saúde Coletiva que merecem um tratamento à parte: quais são os desenvolvimentos, investimentos, fortalecimentos, transformações necessários para que a produção de conhecimentos em Saúde Coletiva se expanda? Que estratégias poderiam ampliar as contribuições do campo? Estas e outras questões poderiam ser analisadas e orientar a elaboração do plano diretor.

Outro ponto essencial para a produção científica, tecnológica e a inovação em saúde como um todo e para a Saúde Coletiva em particular é a criação de instância de fomento no setor saúde, a exemplo das que existem nos países desenvolvidos. Este ponto deve merecer por parte da associação ampla mobilização política objetivando a sua concretização. A criação de uma agência setorial certamente dará maior estabilidade aos avanços já iniciados desde a criação do Departamento de Ciência e Tecnologia (Decit) pelo Ministério da Saúde.

A aprovação da Política Nacional de Ciência, Tecnologia e Inovação em Saúde e da agenda de prioridades em pesquisa, além das atividades desenvolvidas no âmbito do Ministério da Saúde, propõe à associação o desafio de se organizar para avaliar até que ponto essa política chegou a se efetivar, quais as lacunas e limitações em sua implementação e que modificações seriam necessárias para ajustá-la às mudanças ocorridas ao longo do tempo. Com respeito à agenda de prioridades em pesquisa, seria relevante realizar uma avaliação em alguns aspectos, tais como: até que ponto os editais já executados atenderam à agenda da Saúde Coletiva? Qual o peso relativo dos projetos das diferentes áreas que compõem a grande área da saúde? Qual a proporção de projetos financiados em pesquisa 
básica, estratégica ou técnica? Quais são as principais características dos projetos apoiados e que resultados esses projetos apresentaram tendo em vista potenciais impactos sociais e científicos?

A Abrasco poderia ainda desempenhar papel de liderança na articulação entre seus sócios institucionais objetivando a realização de pesquisas multicêntricas que pudessem favorecer a troca de experiências entre os grupos nacionais e o fortalecimento de grupos menos consolidados. O mesmo processo poderia se estender para os países vizinhos criando uma rede de colaboração entre pesquisadores do campo no continente.

No campo da divulgação do conhecimento produzido, é importante que a Abrasco mantenha seu compromisso com o acesso livre como vem fazendo até aqui e busque melhorar a indexação de seus periódicos adotando alternativas que permitam dar maior visibilidade à produção nacional em Saúde Coletiva. No que diz respeito à publicação de livros, forma assumida por cerca de um terço da produção acadêmica da área, a associação poderia desempenhar papel de destaque na negociação com editoras dos países de língua espanhola para tradução e edição dos textos aqui produzidos, ampliando a cooperação com os outros países do continente.

Junto com as outras associações científicas reunidas na SBPC, a Abrasco deverá lutar pela ampliação do orçamento destinado à área de ciência e tecnologia no país, além de denunciar sistematicamente o contingenciamento dos recursos destinados para os fundos setoriais de pesquisa. $\mathrm{O}$ caráter inconstitucional dessa medida adotada sistematicamente pela equipe econômica do governo deve ser argüido visando à liberação dos recursos escassos que por lei deveriam ser destinados à área científica.

Em relação à Política Nacional de Saúde, certamente a Abrasco continuará atuando como um dos interlocutores privilegiados desse processo; entretanto, sua atuação poderá ser ainda mais destacada na medida em que a associação logre responder com agilidade e posicionamentos oportunos aos desafios constantemente apresentados à consolidação e ao aprimoramento do Sistema Único de Saúde.

A criação da Comissão Nacional de Determinantes Sociais em Saúde, da qual a Abrasco participa, constitui uma nova arena para a atuação da associação no âmbito da promoção da saúde e da articulação intersetorial, acenando com a possibilidade de que a atuação no campo político possa extrapolar o Ministério da Saúde e o Sistema Único de Saúde, recuperando o caráter mais amplo de ação política que marcou a prática da entidade em seus primeiros anos.

As questões pendentes em relação ao Sistema Único de Saúde referentes ao financiamento do sistema, à inserção e gestão dos 
trabalhadores e à qualidade dos serviços deverão merecer da Abrasco atenção especial nos próximos anos. O financiamento do SUS será sempre uma questão pendente por pelo menos três motivos: em primeiro lugar, devido ao lento crescimento da economia, a redução significativa dos recursos orçamentários para a saúde; em segundo, as restrições orçamentárias decorrentes do serviço da dívida externa e das despesas com a previdência social; e, finalmente, o encarecimento progressivo do custeio das ações de saúde decorrente da incorporação de inovações tecnológicas. No setor saúde, diferentemente de outros setores econômicos, a introdução de inovações não resulta em redução dos custos, pois as inovações freqüentemente se somam às tecnologias prévias sem substituí-las. Por outro lado, a democratização do Estado possibilita que diferentes grupos de interesses pressionem o governo pela incorporação contínua de inovações.

A Abrasco tem vários papéis a desempenhar nesse aspecto: a articulação política com outros organismos movidos pelos mesmos interesses de defesa das conquistas do SUS; a participação qualificada nos fóruns de controle social como o Conselho Nacional de Saúde; as análises críticas sobre o tema e o incentivo ao desenvolvimento de pesquisas sobre modelos tecnológicos de intervenção que sejam custo-efetivos, por exemplo.

A gestão do trabalho no SUS é outro ponto nevrálgico. A ausência de uma carreira impede que se forme uma burocracia com competência técnica para garantir a qualidade das ações. São justamente as ações coletivas as que mais sofrem o impacto da falta de estabilidade dos profissionais de saúde. O caráter técnico das ações populacionais e a falta de preparo para elas que os profissionais apresentam devido ao enfoque individual dominante na formação fazem com que a atuação em âmbito populacional apresente uma série de insuficiências. A precarização das relações de trabalho não compromete apenas a seguridade social para os trabalhadores e seus dependentes; ela compromete também a qualidade do exercício das funções públicas.

A Abrasco está em condições de formular propostas sobre a gestão do trabalho para os profissionais de Saúde Coletiva e, junto com outras instituições representativas das categorias profissionais, buscar soluções para esse aspecto fundamental no funcionamento do sistema.

A qualidade dos serviços é também um grande desafio. É inegável a extensão de cobertura em atenção básica e assistência hospitalar secundária possibilitada pelo SUS, mas ainda há sérios problemas de desigualdade no acesso à assistência especializada e de alta complexidade, além de muito espaço para a melhoria de qualidade. A Abrasco pode enfrentar essa questão 
incentivando a realização de pesquisas avaliativas, a elaboração de propostas para a organização do trabalho visando à qualidade do atendimento e, principalmente, a formação de profíssionais que tenham a qualidade técnica e a humanização do atendimento entre suas prioridades.

No âmbito organizacional da própria associação, algumas idéias poderiam ser postas em prática para melhorar o desempenho da Abrasco. Uma possibilidade a ser considerada seria a criação de uma assembléia virtual dos sócios institucionais favorecendo a participação permanente e orgânica das instituições associadas nas deliberações e atividades da associação. A articulação permanente entre o trabalho de comissões, grupos temáticos, diretoria e sócios institucionais poderia propiciar dinamismo ainda maior à atuação da Abrasco.

Outro ponto a ser enfrentado é a busca de uma sede mais adequada, assim como a realização de uma forte campanha de filiação, visto que o número de sócios é relativamente pequeno para o tamanho do campo da Saúde Coletiva no país.

Mais um aspecto que poderia melhorar o desempenho da Abrasco seria a 'especialização' das vice-presidências, ou seja, a tentativa de descentralizar as responsabilidades hoje muito centradas na figura do presidente. Se a diretoria tivesse uma nítida divisão de atribuições entre os seus componentes e conseguisse realmente trabalhar de maneira colegiada, certamente haveria a otimização das capacidades e respostas mais oportunas aos diferentes problemas que se apresentam durante cada gestão.

Por mais que 'o feito' seja realmente impressionante diante da infra-estrutura disponível e do pouco tempo de existência da associação, o 'por fazer' é ainda mais desafiador. Felizmente, a Abrasco "somos nós, nossa força e nossa voz", como gosta de ressaltar José Noronha. É o trabalho coletivo e solidário de muitos que permite à Abrasco ocupar o lugar que ocupa na sociedade brasileira, ter a capacidade convocatória que demonstra anualmente ao organizar seus grandes eventos científicos, garantir a produção e a divulgação de conhecimentos científicos com qualidade e, principalmente, ser uma das vozes sempre presentes na defesa da vida com qualidade, da saúde da população brasileira.

\section{FONTES BIBLIOGRÁFICAS}

ABRASCO. Abrasco propõe texto sobre saúde para a Constituinte. Boletim Abrasco, 5(19), 1986.

ABRASCO. Boletim Abrasco, 89, 2003. 
ABRASCO. 25 anos de compromissos e lutas pela saúde dos brasileiros. Transcrição da cerimônia comemorativa dos 25 anos de criação, 2004.

ABRASCO. 25 anos de compromissos e lutas pela saúde dos brasileiros. Boletim Abrasco, 92, 2004.

BELISÁRIO, S. A. Associativismo em Saúde Coletiva: um estudo da Associação Brasileira de Pós-Graduação em Saúde Coletiva - Abrasco, 2002. Tese de Doutorado, Campinas: Pós-Graduação da Faculdade de Ciências Médicas da Universidade Estadual de Campinas (Unicamp). (Mimeo.)

CNPQ PLATAFORMA LATTES 2006. <http://www.cnpq.br>.

COIMBRA JR., C. E. A. Uma conversa com Frederico Simões Barbosa. Cadernos de Saúde Pública, 13(1):145-155, 1997.

COUTINHO, E. M. Frederico Adolfo Simões Barbosa (1916-2004). Revista da Sociedade Brasileira de Medicina Tropical, 37(5):427-428, 2004. 


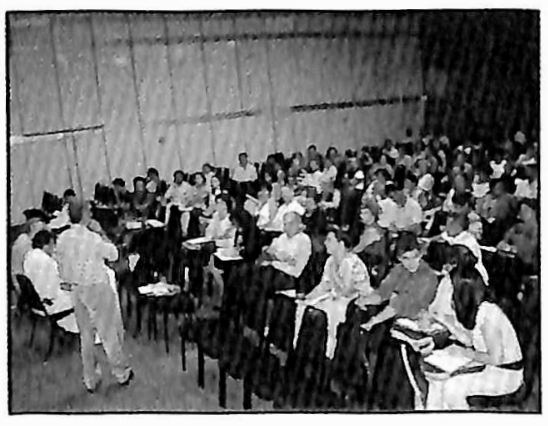

\section{CARTA DE NATAL PEDE EQUIDADE NA SAÚDE}

Comintuito de contribuir com a qualificação da ges tão do SUS e a melhoria da atenção à saúde da população, considerando as diversidades existentes no conjunto dos 5.560 municipios brasileiros, e de incorporar a pauta da cultura da paz e da não violência no conceito da saúde como qualidade de vida, realizou-se o $X X$ Congresso Nacional dos Secretários Municipais de Saúde articulado ao I Congresso Brasileiro de Saúde, Cultura de Paz e Não Violência, reunindo secretários municipais de saúde dó Brasil, na cidade de Natal, Rio Grande do Norte, no período de 18 a 20 de março de 2004.

Considerando as reflexões e debates oconidos durante as mesas e oficinas temáticas, deliberou-se pelas proposições seguintes, que deverão nortear a atuação do CONASEMS, dos COSEMS e dos municípios.

1. Construir um novo pacto da gestão do SUS, que respeite a autonomia das esferas de governo, exija o cumprimento de suas competencias no SUS, e substitua a excessiva normatização e a lógica de habilitação por outra de adesão e de compromissos com resultados.

2. Desenvolver um novo modelo de financiamento que seja balizado pela eqüidade; respeite as especificidades locais e regionais; supere o repasse fragmentado por projetos e programas e estimule a solidariedade entre as três esferas de govemo, garantindo maior participação da esfera estadual. Nesse sentido, reafirma-se, neste momento, apoio irrestrito a regulamentação da Emenda Constitucional 29 que assegure as bases desse mode10 .

3. Definir um conjunto de estratégias e implementar politicas voltadas ao processo de formação e educação permanente dos profissionais de saúde, bem como dos mecanismos de gestão do trabalho, priorizando:

- a criação de um sistema de acreditação para graduação, formação técnica e especialização;

- a criação e manutenção de centros de educação permanente municipais ou loco-regionais e fortalecimento das escolas técnicas;

- o desenvolvimento de politicas de interiorização e fixação de profissionais de saúde (concurso, educação permanente $e$ incentivo monetário);

- o combate a precarização das relações de trabalho;

- a realização de concursos públicos,

- a implantação de planos de cargos, carreiras e salários do SUS com destaque para a carreira nacional SUS de base local;

- O apoio aos dos pólos de capacitação;

- A implantação das mesas de negociação do SUS
- Pactuar na CIT critérios e formas de compensação aos municípios referentes à perda por aposentadoria ou transferência de servidores anteriormente cedidos por outras esferas de governo.

4. Reafirmar a importância da organização da atenção à saúde, através de:

- qualificação da atenção básica, com estratégias que trabalhem o princípio da integralidade da atenção mediante a adscrição, ternitorialização, vínculo e acolhimento;

- respeito à diversidade na forma de organização de serviços e regionalização;

- atenção especial às populações e grupos mais vulneráveis:

- constituição de redes assistenciais articuladas e solidárias entre si;

- constituição de complexos regulatórios, que utilizam o critério de necessidade para garantia de acesso com equidade. Para tanto é necessária a implantação de centrais de regulação ambulatorial, hospitalar e de urgência, sob comando do gestor municipal, financiado pelas três esferas de governo, através recursos para implantação e manutenção destes complexos;

- implementação imediata das ações inseridas na política de informação e informática da saúde, principalmente no que diz respeito à efetiva implantação do cartão SUS e a racionalização e simplificação dos sistemas de informação $e$

- Sensibilização dos órgãos competentes para garantir a cobertura dos serviços de telefonia em todos os municípios brasileiros.

5. Reafirmar o total apoio às instâncias de pactuação /Comissões Intergestores bi e tripartite le o efetivo Controle Social através dos Conselhos Municipais, Estaduais e Nacional de saúde, enfatizando as deliberações da XII Conferência Nacional de Saúde.

- Incorporar os princípios da cultura de paz e não violência:

- na adoção da intersetorialidade caracterizada pelo estabelecimento de redes de solidariedade para a construção de novas práticas sociais visando o desenvolvimento e a promoção da saúde da população como qualidade de vida;

- maior envolvimento e participação do setor saúde com os movimentos sociais locais $e$

- nas relações cotidianas da atenção à saúde entre equipes, profissionais e população atendida.

- Como forma de encaminhamento não só das proposjções aqui colocadas, mas de todas as propostas e sugestões formuladas pelos grupos de trabalho, serão encaminhados todos os relatórios finais aos núcleos temáticos do CONASEMS que embasarão a conduta da entidade nos pactos formalizados no âmbito da Comissão Intergestores Tripartite

Natal, 20 de marco de 2004

Boletim Abrasco 


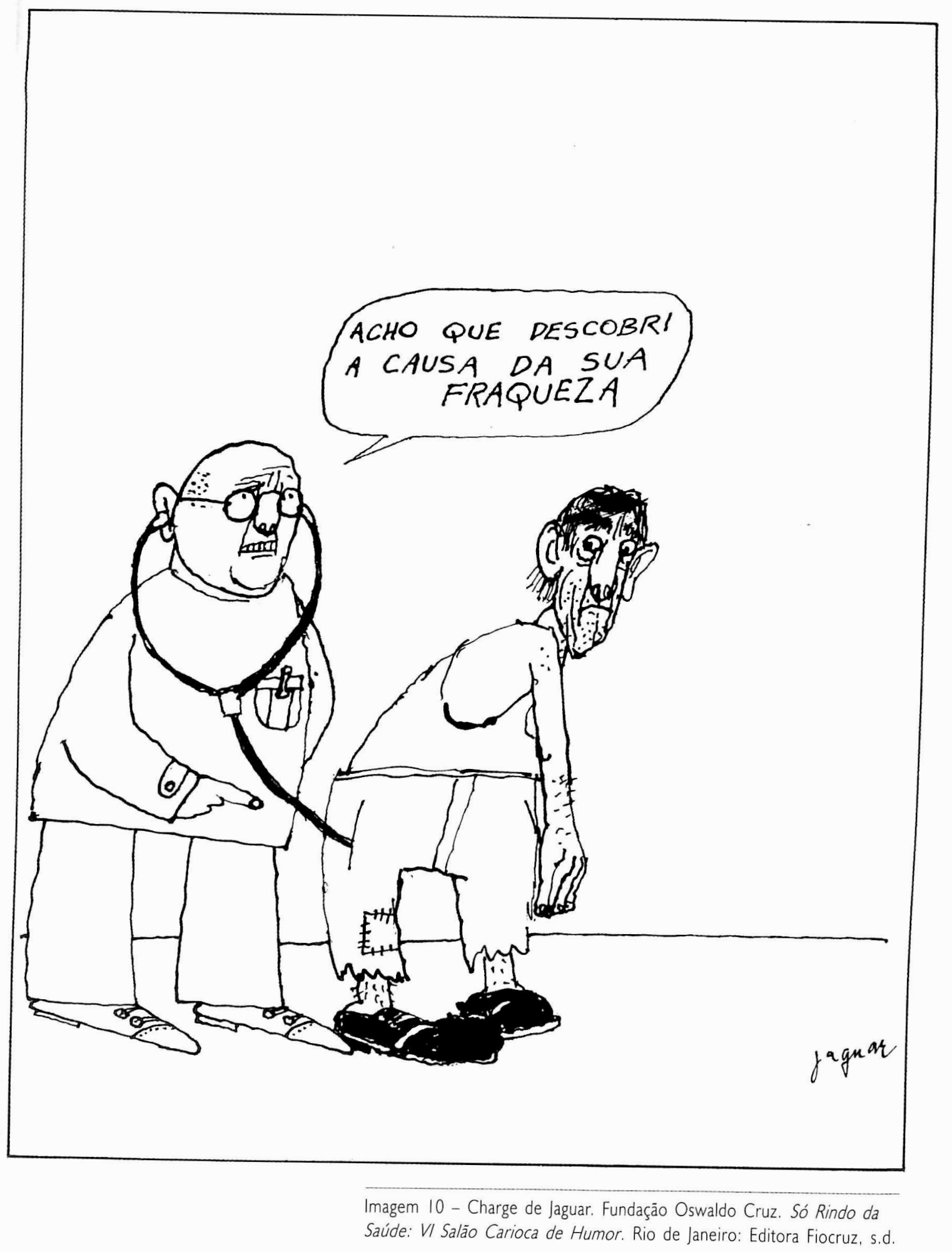




\section{O SUS no ano 2000:}

\section{Novos rumos, antigos (des)caminhos?}

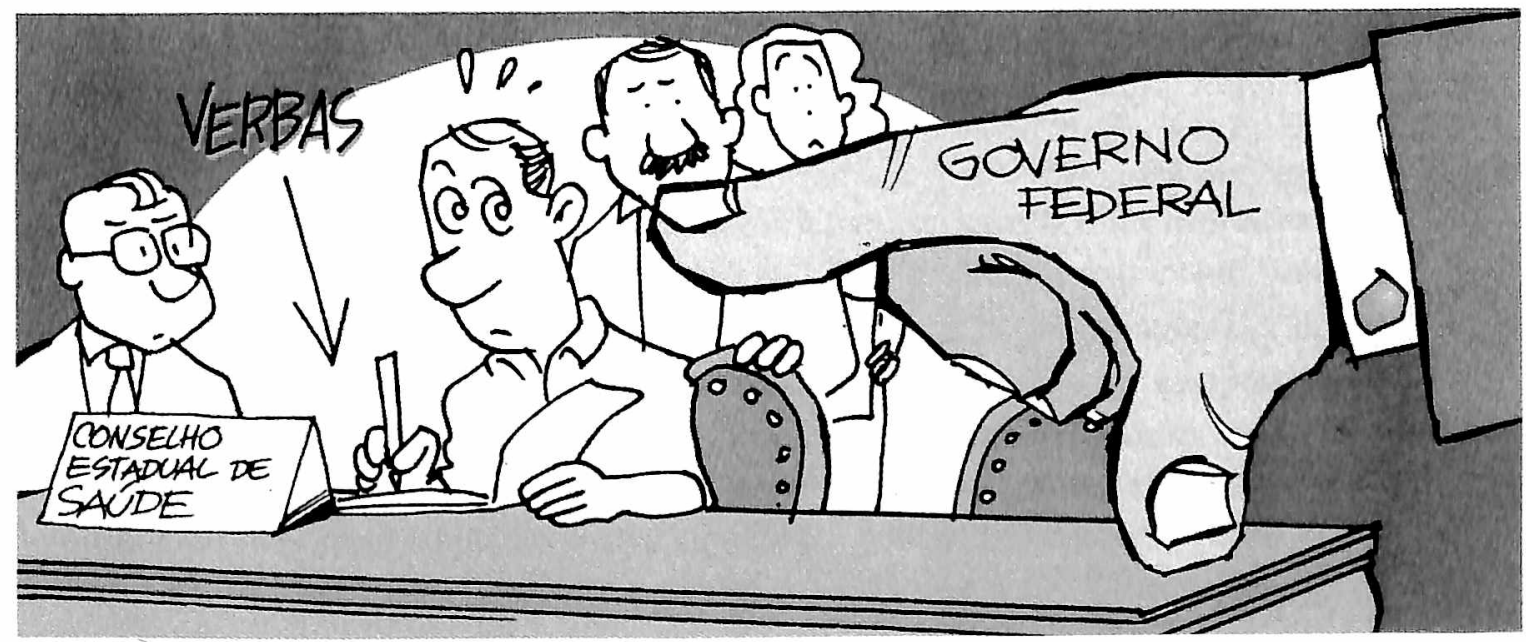

Imagem II - Charge de Tibúrcio publicada no Boletim Abrasco, 77 , abr.-jun.2000, p. I, referente ao editorial. 